\title{
RELATIONSHIP BETWEEN STEM BIOMASS AND VOLUME OF Pinus caribaea IN THE YAGIRALA FOREST RESERVE
}

\author{
A.M.R. Haripriya \& S.M.C.U.P.Subasinghe \\ Department of Forestry and Environmental Science, \\ University of Sri Jayewardenepura
}

The biomass is an important mcasurement in commercial forcstry maintained to produce pulp, paper, chips, fuel wood products etc. The estimation of the biomass of the tree is not an casy task and few studies were carried out so far.

The present study was conducled in the 25 years old Pinus caribaea plantation in Yagirala Forest Reserve, which is in the low country wet zonc. According to the geographical differences in the plantation, i.c., valley, slopes and ridge, stratified random sampling was carried out and two 0.05 ha circular plots were established in each stratum. Altogether 6 plots were used for the data collection.

The diameter at breast height (dbh), total height were measured for all the trees in these plots and after dividing the tree stem into several sections, the length and end and mid diameters of each section was measured using the Spicgel relaskop.

The volume of the stem was estimated by calculating section volumes. Smalian's and Newton 's formula were used to estimate the section volumes except for the final section at the top, which was assumed as a cone. In order to save time, one plot was measured for Newton's formula and the rest was measured for Smalian's formula. Then a relationship was build to estimate Newton's volume ( $\mathrm{Ne}$ ) using Smalian's volume ( $\mathrm{Sm}$ ) as the explanatory variable (equation 1 ). The $\mathrm{R}^{2}$ value was $99.9 \%$.

$$
\mathrm{Ne}=0.976^{*} \mathrm{Sm}
$$

Biomass of the tree was estimated by extracting core samples at the breast height and mid height of the tree. The density of the core samples were estimated using oven dry weight and the green volume of the core samples. When tested, there was no significant difference of the density along the stcm. Therefore stem biomass was cstimated using the density at the breast height, and the total stem volume. Also there was no significant density differences between three sites.

The regression analysis was used with the poolcd data to find out the relationship between the stem biomass $(W)$ and the volume $(V)$. Using variable of stem volume and the biomass and its tranformations developed the several models. The best model was selected by checking the $\mathrm{R}^{2}$ value, standard residual distribution, modelling efficiency and bias. The

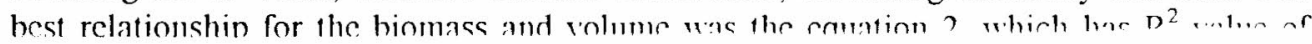

